University of South Carolina

Scholar Commons

\title{
Physical Activity and Sedentary Activity Patterns Among Children and Adolescents: A Latent Class Analysis Approach
}

\author{
Carrie D. Patnode \\ Leslie A. Lytle \\ Darin J. Erickson \\ John R. Sirard \\ Daheia J. Barr-Anderson \\ University of South Carolina - Columbia, barra027@umn.edu
}

See next page for additional authors

Follow this and additional works at: https://scholarcommons.sc.edu/

sph_epidemiology_biostatistics_facpub

Part of the Public Health Commons

Publication Info

Published in Journal of Physical Activity and Health, Volume 8, Issue 4, 2011, pages 457-467.

Patnode, C. D., Lytle, L. A., Erickson, D. J., Sirard, J. R., Barr-Anderson, D. J., \& Story M. (2011). Physical activity and sedentary activity patterns among children and adolescents: A latent class analysis approach. Journal of Physical Activity and Health, 8(4), 457-467. (c) Journal of Physical Activity and Health, 2011, Human Kinetics

This Article is brought to you by the Epidemiology and Biostatistics at Scholar Commons. It has been accepted for inclusion in Faculty Publications by an authorized administrator of Scholar Commons. For more information, please contact digres@mailbox.sc.edu. 


\section{Author(s)}

Carrie D. Patnode, Leslie A. Lytle, Darin J. Erickson, John R. Sirard, Daheia J. Barr-Anderson, and Mary Story 


\title{
Physical Activity and Sedentary Activity Patterns Among Children and Adolescents: A Latent Class Analysis Approach
}

\author{
Carrie D. Patnode, Leslie A. Lytle, Darin J. Erickson, John R. Sirard, \\ Daheia J. Barr-Anderson, and Mary Story
}

\begin{abstract}
Background: While much is known about the overall levels of physical activity and sedentary activity among youth, few studies have attempted to define clusters of such behaviors. The purpose of this study was to identify and describe unique classes of youth based on their participation in a variety of physical activity and sedentary behaviors. Methods: Latent class analysis was used to characterize segments of youth based on patterns of self-reported and accelerometer-measured participation in 12 behaviors. Children and adolescents $(\mathrm{N}=720)$ from 6th-11th grade were included in the analysis. Differences in class membership were examined using multinomial logistic regression. Results: Three distinct classes emerged for boys and girls. Among boys, the 3 classes were characterized as "Active" (42.1\%), "Sedentary" (24.9\%), and "Low Media/Moderate Activity" (33.0\%). For girls, classes were "Active" (18.7\%), "Sedentary" (47.6\%), and "Low Media/Functional Activity" (33.7\%). Significant differences were found between the classes for a number of demographic indicators including the proportion in each class who were classified as overweight or obese. Conclusions: The behavioral profiles of the classes identified in this study can be used to suggest possible audience segments for intervention and to tailor strategies appropriately.
\end{abstract}

Keywords: exercise, youth, health behavior

Physical activity (PA) is crucial for children's normal growth and development; the lack of which is a well-established risk factor for several chronic health outcomes, including obesity. ${ }^{1-5}$ Given that PA habits formed early in life may continue into adulthood, regular participation in PA during childhood and adolescence is of critical importance. There are many different types of activities and ways in which activity patterns can be described, including time spent in structured versus unstructured PA, specific types of activities and sports, weekday versus weekend involvement, as well as participation in sedentary pursuits. While most research revolves around the frequency and duration with which youth participate in these activities, understanding the details, patterns, and types of activities that young people participate in may help elucidate what determines total involvement and how specific types of activity may contribute to greater health outcomes.

\footnotetext{
Patnode is with the Center for Health Research, Kaiser Permanente, Portland, OR. Lytle, Erickson, and Story are with the Dept of Epidemiology and Community Health, University of Minnesota, Minneapolis, MN. Sirard is with the Kinesiology Program, Curry School of Education, University of Virginia, Charlottesville, VA. Barr-Anderson is with the School of Kinesiology, University of Minnesota, Minneapolis, MN.
}

To develop effective interventions, beginning with a clear definition of who one's audiences are, is essential. ${ }^{6-8}$ Audience segmentation is a process by which a broad population is divided into a smaller number of homogeneous subgroups, known as segments, based on meaningful patterns of behaviors or attitudes. When such groups are identified and understood, targeted interventions can be developed to address their unique characteristics and needs. Unfortunately, typical strategies for segmenting audiences are often based on simple demographic or geographic characteristics rather than theory or empirical evidence.

Latent class analysis (LCA) is one statistical tool that offers considerable promise in audience segmentation methods. A growing number of public health studies have applied LCA to successfully identify behavioral typologies of substance use, ${ }^{9-11}$ smoking, ${ }^{12}$ and dietary behaviors; ${ }^{13-15}$ however, to date, no studies have been published that have applied LCA to children and adolescent's PA and sedentary behaviors. Using LCA, Metzger and colleagues ${ }^{16}$ assessed whether patterns or classes exist among adults based on accelerometer-measured PA data from the 2003 to 2004 National Health and Nutrition Examination Survey. Five classes of PA patterns were determined based on daily bouts and minutes spent in PA. The authors of this study concluded that a substantial portion of the US population of adults would be classified into patterns of PA that represent low levels throughout the week. 
The purpose of this study was to identify homogeneous classes of children and adolescents based on their participation in a variety of PA and sedentary behaviors and to describe the classes based on demographic characteristics. It was hypothesized that among children and adolescents, there are distinct subgroups, and that the identification and characterization of these segments can aid in the development of interventions tailored to their specific needs.

\section{Methods}

\section{Study Population}

Data for this study are from baseline data collected as part of 2 separate cohort studies: the Identifying Determinants of Eating and Activity in Adolescents (IDEA) study ${ }^{17}$ and the Etiology of Childhood Obesity (ECHO) study. Both studies were designed to examine the potential risk and protective factors of childhood obesity at the individual, family, home, school, and neighborhood levels and included identical measurement protocols and instruments. Recruitment procedures and the timing of data collection differ for the 2 studies and the samples included are independent. Given that the measurement procedures were identical for these 2 studies, the cohorts were combined for this analysis to provide a larger, more diverse sample.

For the IDEA study, data were collected annually over 24 months on a cohort of youth aged 11 to 17 years old at baseline and 1 significant adult (a parent or guardian with whom they spent a significant amount of time). Time 1 (baseline) data collection took place from November 2006 through May 2007. Youth were recruited from within the 7-county metropolitan area of Minneapolis/ St. Paul, Minnesota via 3 recruitment strategies: (1) an existing cohort of children and adolescents participating in the Minnesota Adolescent Community Cohort (MACC) tobacco study, ${ }^{18}$ (2) a Minnesota Department of Motor Vehicle list, and (3) a convenience sample drawn from local communities. ${ }^{17}$ The ECHO study is designed to collect data at 2 time points over 3 years on a cohort of youth aged 10 to 16 years old at baseline and 1 significant adult. Time 1 or baseline data collection for the ECHO study took place from September 2007 to May 2008; time 2 is scheduled for September 2009 to May 2010. Youth and parents for the ECHO study were recruited through HealthPartners, a managed care organization in Minnesota. Recruitment was designed to enroll a sample representing both healthy and overweight youth and adults and higher racial/ethnic diversity than the IDEA study. For both studies, youth were ineligible to participate if they planned to move from the area in the next 3 years, had a medical condition that affected their growth, were non-English speaking, and/or had any other physical or emotional condition that would affect their diet/activity levels or make it difficult to complete measurements.

\section{Measures}

For both studies, all measurements were completed during a 2-hour clinic visit and via several take-home instruments. Clinic visits were scheduled MondayThursday and on Saturdays, thus, the specific days of the week that each child recalled or completed measurements was different. During each clinic visit, youth and their parent were given brief background on the study, confirmed consent and assent, and then were separated for subsequent measures (eg, self-administered surveys, anthropometric measures) administered by trained data collectors. The University of Minnesota Institutional Review Board approved all recruitment, consent and measurement protocols for the IDEA and ECHO studies.

Physical Activity-Accelerometers. Average minutes per day spent in moderate-to-vigorous physical activity (MVPA) on weekdays and weekend days was measured with the use of uniaxial accelerometers, specifically the ActiGraph model 7164 (ActiGraph, Pensacola, FL). The ActiGraph has been shown to have high interinstrument reliability and to be valid in samples of children and adolescents. ${ }^{19}$ At each clinic visit, children were fitted with the accelerometer and were instructed to wear it during waking hours for a total of 7 days. Participants were given postage-paid envelopes and were asked to mail the monitor directly back to data collection staff, who subsequently downloaded all data.

A number of exclusion and inclusion criteria were specified to reduce the accelerometer data. First, 30 minutes of consecutive counts of ' 0 ' were used to indicate that the accelerometer was not being worn and these data points were excluded. Next, days with less than 8 hours of data were excluded from the analysis to account for unrepresentative days of activity. Participants with at least 3 out of 5 weekdays and at least 1 weekend day of valid data were included in their respective analyses.

The number of accelerometer counts recorded were used to estimate and categorize the data by intensity level to provide minutes per day spent in MVPA based on the age-specific equation of Freedson et al (2005). ${ }^{20}$ The convention of Troiano et $\mathrm{al}^{21}$ was used where MVPA equals 4 METs (metabolic equivalents) or greater. Mean minutes of PA was then dichotomized with ' 1 ' indicating less than 30 minutes of MVPA per day and ' 2 ' indicating 30 minutes or more per day. The 30 minute criterion was chosen as opposed to the recommended 60 minutes $^{2}$ as youth in this sample were only participating in a mean of 29 minutes and 21 minutes of MVPA on weekdays and weekend days, respectively. A parallel recoding scheme was adopted for all of the following dichotomized behaviors, with ' 1 ' representing lower levels or no participation and ' 2 ' representing higher levels in the given activity.

Physical Activity-3-Day Physical Activity Recall. The 3DPAR was used as another measure of PA of youth. ${ }^{22}$ For each of the 3 days preceding their clinic visit, participants indicated their main activity performed during 
30-minute time blocks beginning at $6 \mathrm{AM}$ and ending at midnight. The full 3DPAR included a list of 70 commonly performed activities. For this study, 44 relevant activities of similar characteristics were grouped together. The category of traditional sports included 14 activities such as basketball, cheerleading, and hockey. Fitness activities included 11 activities like aerobics, weightlifting, and yoga. The category of other sports and PA included 15 activities such as playing active games, skiing, and skateboarding. Lastly, chores/work included playing with children, working, doing house chores, and yard work. Youth were considered a participant in a specific category of activities if they reported engaging in that activity for at least 130 -minute session over the 3 days recalled. Assessing PA over multiple days, as done here, has been shown to provide reliable and valid estimates of usual activity in children as young as the fifth-grade..$^{23,24}$

Sedentary Behaviors-Student Survey. Sedentary behaviors were measured with self-administered surveys using items adapted from the Planet Health ${ }^{25}$ and Project EAT ${ }^{26}$ studies. Participants were asked how many hours they spend (1) watching TV, (2) watching DVDs or videos, (3) reading/homework, (4) Nintendo/Play Station/computer games, (5) internet/computers, and (6) talking on the phone or cell phone/text messaging for both typical weekdays and weekend days. Categorical response options included $1=$ none, $2=$ less than $1 / 2$ hour, $3=1 / 2$ hour to 2 hours, $4=21 / 2$ hours to 4 hours, $5=41 / 2$ hours to 6 hours, and $6=6$ hours or more. These categorical response options were converted to the mean minutes represented by each category (ie, 1 $=0$ minutes, $2=15$ minutes, $3=75$ minutes, $4=195$ minutes or 3 hours and 15 minutes, $5=315$ minutes or 5 hours and 15 minutes, and $6=360$ minutes or 6 hours) and time per average weekday and average weekend day were summed and weighted according to day of the week to calculate the total number of hours per day spent in each of the sedentary behaviors. Each activity was then dichotomized according to national recommendations (ie, 2 hours for TV watching) ${ }^{27}$ and by conceptually and empirically appropriate splits (ie, 1 hour for video games and 2 hours for reading).

Demographic and Anthropometric Information. Demographic information of youth gender, date of birth, grade, race/ethnicity, and family living arrangements were self-reported by children on the student survey. Parents reported their highest level of education and whether their child qualified for free or reduced-price lunch. Trained and certified staff members collected height and weight data. Height was measured with children barefoot, using a direct reading, portable stadiometer (Shorr Productions, Olney, MD); body weight was measured barefoot and wearing light clothing, using an electronic scale/body composition analyzer (Tanita TBF-200A; Tanita Corporation of America, Inc., Arlington Heights, IL). The average of 2 height values and 2 weight values was used to calculate body mass index (BMI).

\section{Statistical Analysis}

Given the identical protocols and measurements, baseline data for the IDEA and ECHO cohort studies were combined for analyses. The underlying classes were determined based on youth's participation in 12 activities: (1) MVPA on weekdays, (2) MVPA on weekend days, (3) traditional sports, (4) fitness activities, (5) other sports and PA, (6) chores/work, (7) watching television (TV), (8) watching DVDs or videos, (9) playing video games or computer games, (10) using the Internet/computer, (11) talking or texting on the phone, and (12) reading/ homework. Table 1 presents each of the variables, their source, and how they were categorized.

Descriptive statistics were calculated, and the prevalence of each of the $12 \mathrm{PA}$ and sedentary behaviors were examined for the total sample and for boys and girls, separately. Differences in the prevalence of each behavior between boys and girls were assessed using chi-square tests. To examine the structure underlying the set of 12 PA and sedentary behaviors, LCA was performed using SAS PROC LCA (SAS version 9.1, Cary, NC: SAS Institute Inc.). ${ }^{28}$ LCA is a statistical method that is used to estimate the number of latent (ie, constructs that cannot be observed directly) homogeneous classes in a heterogeneous sample based on the pattern of responses on 2 or more observed variables. ${ }^{29}$ The parameters that are estimated in a latent class model are (1) the proportion of the sample composing each class (latent class prevalence) and (2) the probability of reporting each behavior within a particular latent class (response probabilities). In PROC LCA, missing data are managed by maximum likelihood using an EM (expectation-maximization) procedure, with data assumed to be missing at random. ${ }^{28}$

To select the appropriate number of classes and maximize model fit, a series of latent class models were fit to the data. First, the most parsimonious 1-class model ("all youth the same") was fit and then successive models with an increasing number of latent classes (up to 6) were estimated. To detect any model identification problems, 100 iterations of each model was run using randomly generated seed values. The resulting likelihood ratio values $\left(\mathrm{G}^{2}\right)$ were compared across the 100 iterations and the solution which most frequently resulted in the same $\mathrm{G}^{2}$ value was identified as the maximum likelihood solution. ${ }^{28}$

Determining the proper number of classes that adequately described the sample was based on an examination of statistical fit indices and conceptual considerations. First, the $\mathrm{G}^{2}$ statistic was examined in relation to the degrees of freedom for each model. Generally, if the $\mathrm{G}^{2}$ estimates are less than the model's degrees of freedom than the model is identified as having reasonably good fit. ${ }^{30}$ However, because models with different number of 
Table 1 Physical Activity and Sedentary Behavior Variables Entering the Latent Class Analysis

\begin{tabular}{lll}
\hline Data source & Variable & Measurement \\
\hline Accelerometer & (1) MVPA-weekdays & $1=<30$ min per day, $2=\geq 30$ min per day \\
(2) MVPA—weekend days & $1=<30$ min per day, $2=\geq 30$ min per day \\
3DPAR & (3) Traditional sports & $1=<1$ session/3 days, $2=\geq 1$ session/3 days \\
& (4) Fitness activities & $1=<1$ session/3 days, $2=\geq 1$ session/3 days \\
(5) Other sports/physical activities & $1=<1$ session/3 days, $2=\geq 1$ session/3 days \\
(6) Chores/work & $1=<1$ session/3 days, $2=\geq 1$ session/3 days \\
Student survey & & $1=<2$ hours per day, $2=\geq 2$ hours per day \\
& (7) Watching TV & $1=<1$ hours per day, $2=\geq 1$ hours per day \\
(8) Watching DVDs or videos & $1=<1$ hours per day, $2=\geq 1$ hours per day \\
(9) Playing video or computer games & $1=<1$ hours per day, $2=\geq 1$ hours per day \\
(10) Using the Internet/computer & $1=<1$ hours per day, $2=\geq 1$ hours per day \\
(11) Talking/texting on the phone & $1=<2$ hours per day, $2=\geq 2$ hours per day \\
\hline
\end{tabular}

Abbreviations: MVPA, moderate-to-vigorous physical activity; TV, television; DVD, digital video disc.

latent classes are not nested it prevents the use of a likelihood ratio chi-square test. Therefore, other fit statistics, namely the Akaike Information Criterion (AIC) ${ }^{31}$ and the Bayesian Information Criterion (BIC) ${ }^{32}$ were examined. In comparing different models with the same set of data, models with lower values are preferred. Lastly, theoretical implications and distinctiveness of each latent class profile was examined to guide decisions regarding the appropriate number of classes. The aim was to have high correspondence between established classes and some practical interpretation of what the classes indicated.

Given the known differences in PA and sedentary habits betweens boys and girls, ${ }^{33-36}$ a nested, multigroup LCA procedure was run based on the number of latent classes identified in the full sample. Comparisons were made between a freely estimated model (unrestricted model) and a model where parameter estimates were restricted across groups (ie, boys and girls). Lastly, youth were assigned to the class in which they had the highest posterior probability of membership (ie, the maximumprobability assignment rule). The average posterior probability of membership was calculated for each class, given class assignment, to assess the reliability of the LCA class assignments (ie, values close to 1 indicate good classification accuracy). Demographic characteristics were compared among each of the emergent latent classes using chi-square procedures and latent multinomial logistic regression. These analyses served to characterize the classes more clearly, as well as to provide evidence that there were meaningful differences between the classes.

\section{Results}

\section{Descriptive Characteristics of the Sample}

Table 2 presents characteristics of the children and adolescents enrolled in the IDEA and ECHO studies.
In total, 720 youth are included in these analyses with a mean age of 14.7 years. Youth were in grades 6 to 11 (46.5\% in 6th to 8 th grade and $53.5 \%$ in 9th to 11 th grade) and roughly half were male $(48.9 \%)$. Nearly $85 \%$ of the analysis sample was white and the majority of parents had a college degree or training beyond college (64.1\%). Approximately $13 \%$ of the sample was classified as overweight (BMI $\geq 85$ th $<95$ th percentile) and another $13 \%$ were considered obese (BMI $\geq 95$ th percentile) according to the 2000 Centers for Disease Control and Prevention BMI-for-age growth charts. ${ }^{37,38}$

Prevalence estimates for each of the 12 behaviors as well as means and standard deviations are shown in Table 3. Prevalence ranged from 22.9\% (MVPA for 30 minutes or more on weekend days) to $53.8 \%$ (using the computer or Internet for an hour or more per day). Boys participated in significantly more MVPA on both weekdays and weekend days and in traditional sports and reported higher levels of watching TV and playing video games than girls. Girls reported participating in more chores and work activities, talking or texting on the phone, and reading/homework than boys.

\section{Estimation of the Number of Latent Classes}

Model fit indices for each of the 6 models (ie, 1 to 6 classes) suggested that the latent class model consisting of 3 classes (3-class) was the most appropriate model for the data. Table 4 presents the fit indices for each of the 6 models. The 3-class model had a BIC score (2280.44) similar to the 2-class model (2279.17) and lower than the 4-class (2313.49) solution. The AIC values decreased toward the 3 -class solution and continued to decrease slightly thereafter. In addition to these empirical measures, the 3-class model was chosen as the final model for reasons of ease of class interpretability and conceptual meaning. 
Table 2 Sample Characteristics

\begin{tabular}{|c|c|c|c|}
\hline & $\begin{array}{c}\text { IDEA study } \\
(n=347)\end{array}$ & $\begin{array}{c}\text { ECHO study } \\
(n=373)\end{array}$ & $\begin{array}{c}\text { TOTAL sample } \\
(\mathrm{N}=720)\end{array}$ \\
\hline Characteristic & $\%$ & $\%$ & $\%$ \\
\hline Age, mean (SD) & $15.4(1.7)$ & $14.0(1.7)$ & $14.7(1.8)$ \\
\hline \multicolumn{4}{|l|}{ Grade } \\
\hline 6th-8th & 30.3 & 61.7 & 46.5 \\
\hline 9th-11th & 69.7 & 38.3 & 53.5 \\
\hline Gender, boys & 49.0 & 48.8 & 48.9 \\
\hline Race/ethnicity, White & 93.7 & 76.4 & 84.7 \\
\hline \multicolumn{4}{|l|}{ Parental education } \\
\hline Some college or less & 35.8 & 36.0 & 35.9 \\
\hline College degree or more & 64.2 & 64.0 & 64.1 \\
\hline Live with 2 parents/guardians & 80.1 & 71.1 & 75.4 \\
\hline Receive free or reduced-price lunch & 7.8 & 15.8 & 11.9 \\
\hline \multicolumn{4}{|l|}{ Weight status ${ }^{\mathrm{a}}$} \\
\hline Underweight & 1.2 & 1.6 & 1.4 \\
\hline Healthy weight & 79.0 & 67.3 & 72.9 \\
\hline Overweight & 12.1 & 13.7 & 12.9 \\
\hline Obese & 7.8 & 17.4 & 12.8 \\
\hline
\end{tabular}

a Weight status categories based on the 2000 CDC BMI-for-age growth charts.

Note. Underweight $\leq 5$ th percentile, Healthy weight $=5$ th to $<85$ th percentile, Overweight $=85$ th to $<95$ th percentile, Obese $\geq 95$ th percentile.

Table 3 Descriptive Statistics of Key Behaviors

\begin{tabular}{|c|c|c|c|c|c|c|c|}
\hline \multirow[b]{2}{*}{ Behavior } & \multicolumn{3}{|c|}{ Prevalence } & \multicolumn{3}{|c|}{ Mean (SD) } & \multirow[b]{2}{*}{$\boldsymbol{P}$} \\
\hline & Total & Boys & Girls & Total & Boys & Girls & \\
\hline MVPA-weekdays, $\geq 30 \mathrm{~min} /$ day & 38.3 & 46.1 & 30.9 & $29.2(19.4)$ & $33.3(22.0)$ & $25.3(15.6)$ & $<0.0001$ \\
\hline MVPA-weekend days, $\geq 30 \mathrm{~min} /$ day & 22.9 & 31.2 & 14.8 & $21.9(2.4)$ & $26.4(25.1)$ & $16.1(16.7)$ & $<0.0001$ \\
\hline Traditional sports, $\geq 1$ sessions $/ 3$ days & 42.9 & 49.7 & 36.4 & $3.2(5.2)$ & $3.9(5.7)$ & $2.5(4.5)$ & 0.0002 \\
\hline Fitness activities, $\geq 1$ sessions $/ 3$ days & 40.0 & 40.1 & 40.0 & $1.7(3.0)$ & $1.9(3.4)$ & $1.6(2.6)$ & 0.2003 \\
\hline Other sports/playing, $\geq 1$ sessions $/ 3$ days & 41.0 & 41.2 & 40.8 & $2.6(5.2)$ & $2.8(5.7)$ & $2.3(4.6)$ & 0.1759 \\
\hline Chores/work, $\geq 1$ sessions/ 3 days & 44.7 & 40.6 & 48.6 & $3.0(5.7)$ & $2.5(4.9)$ & $3.5(6.4)$ & 0.0297 \\
\hline Watching TV, $\geq 2$ hrs/day & 32.5 & 36.7 & 28.5 & $114.7(93.3)$ & $123.5(95.0)$ & $106.3(91.1)$ & 0.0135 \\
\hline Watching DVDs or videos, $\geq 1$ hrs/day & 34.5 & 31.9 & 37.0 & $55.7(61.1)$ & $51.8(59.2)$ & $59.4(62.7)$ & 0.0936 \\
\hline Video/computer games, $\geq 1 \mathrm{hrs} /$ day & 29.5 & 46.3 & 13.4 & $53.6(84.0)$ & $83.1(96.0)$ & $25.4(58.2)$ & $<0.0001$ \\
\hline Internet/computers, $\geq 1 \mathrm{hrs} /$ day & 53.8 & 49.4 & 57.9 & $93.6(94.6)$ & $86.9(94.3)$ & $100.1(94.6)$ & 0.0615 \\
\hline Talking/texting on phone, $\geq 1 \mathrm{hrs} /$ day & 37.2 & 28.1 & 45.9 & $78.8(108.6)$ & $54.2(85.1)$ & $102.3(122.7)$ & $<0.0001$ \\
\hline Reading/homework, $\geq 2$ hrs/day & 47.2 & 39.7 & 54.4 & $143.2(104.7)$ & $122.6(96.0)$ & $162.6(109.0)$ & $<0.0001$ \\
\hline
\end{tabular}

Abbreviations: MVPA, moderate-to-vigorous physical activity; TV, television; DVD, digital video disc.

Note. Total sample $=720$, though sample sizes for individual analyses vary slightly due to missing data. Differences between boys and girls assessed via $t$ test.

Table 4 Criteria to Assess Model Fit for LCA Models

\begin{tabular}{lcccc}
\hline Number of classes & G $^{2}$ & DF & AIC & BIC \\
\hline 1 & 2269.44 & 4083 & 2293.44 & 2348.39 \\
2 & 2114.69 & 4070 & 2164.69 & 2279.17 \\
3 & 2030.43 & 4057 & 2106.43 & 2280.44 \\
4 & 1977.95 & 4044 & 2079.95 & 2313.49 \\
5 & 1945.19 & 4031 & 2073.19 & 2366.26 \\
6 & 1918.32 & 4018 & 2072.32 & 2424.92 \\
\hline
\end{tabular}

Abbreviations: $\mathrm{G}^{2}$, Likelihood ratio chi-square; DF, degrees of freedom; AIC, Akaike Information Criterion, BIC, Bayesian Information Criteria. Note. Models with lower values are preferred. 


\section{Measurement Invariance Across Gender Groups}

To test for measurement invariance among boys and girls, model fit was compared between the 2 nested models by examining the difference in the $\mathrm{G}^{2}\left(\mathrm{G}^{2}\right.$ restricted $-\mathrm{G}^{2}$ unrestricted $=101.9)$ to a chi-square distribution with degrees of freedom (df) equal to the difference in degrees of freedom $\left(\mathrm{df}_{\text {restricted }}-\mathrm{df}_{\text {unrestricted }}=36\right)$. The significant $P$ value $(P<$ .0005 ) suggested that the null hypothesis of measurement invariance should be rejected and that modeling should be conducted separately for boys and girls. ${ }^{28}$ Models were subsequently reestimated for boys and girls separately to provide group-specific interpretations of the 3 latent classes for both groups.

\section{Latent Class Profiles}

Table 5 presents the results of the stratified LCA, including the proportion of boys and girls in each class (latent class prevalence) and the probability of reporting each of the 12 behaviors within a particular latent class (itemresponse probabilities). The estimated probabilities for each of the emergent classes are also displayed graphically in Figure 1 to aid interpretation.

Latent Classes of Boys. Among boys, class 1 accounted for $42.1 \%$ of the sample and was distinguished from other classes as being the "Active" class. Boys in this class were more likely to participate in higher levels of MVPA on both weekdays (item-response probability: 0.76 ) and weekend days (0.62) and have the highest probability of participating in traditional sports $(0.59)$ and fitness activities $(0.44)$. Class 2 represented about a quarter $(24.9 \%)$ of the sample of boys and can be characterized by their high participation in screen media activities and reading/homework. For example, boys in class 2 had the highest probability of watching TV for 2 or more hours per day (0.70), playing video or computer games (0.86), using the Internet or computer (0.72), and watching DVDs or movies (0.64) for an hour or more per day, and for reading or doing homework for 2 or more hours (0.55). On the other hand, boys in this class had relatively low probabilities of participating in PA, particularly on the weekend (0.17). As such, class 2 for boys was labeled as the "Sedentary" class.

Class 3 accounted for $33.0 \%$ of boys, and was the second largest of the 3 boy classes. Class 3 was considered the "Low Media/Moderate Activity" class as boys in this group tended to have relatively low to moderate probabilities of participating in almost all of the behaviors examined. Within this class, their highest probabilities were for Internet/computer use (0.51), reading/homework (0.42), and traditional sports (0.47), although this group of boys had low tendencies to participate in MVPA on both weekdays (0.10) and weekend days (0.03). Within all 3 classes of boys, the probability of talking or texting on the phone for an hour or more per day was generally low.

Latent Classes of Girls. Three distinct classes among girls were also identified. Class 1 of girls was similar to class 1 among boys and can be referred to as the "Active" class. While more over two-fifths of boys were categorized in the parallel boys' Active class, less than one-fifth $(18.7 \%)$ of the girls in this sample were in this segment. Girls in class 1 had the highest probabilities for MVPA for at least 30 minutes on both weekdays (0.74) and weekend days (0.68) and were more likely to participate in traditional sports (0.56) and fitness activities $(0.54)$ than girls in the other 2 classes. The likelihood of reading or doing homework was also relatively high for this group of girls (0.58).

Table 5 Response Probabilities for Each of the 12 Behaviors by Each of the Latent Classes

\begin{tabular}{lccccccc}
\hline & \multicolumn{3}{c}{ Item-response probabilities within each class } \\
\cline { 2 - 3 } & \multicolumn{3}{c}{ Boys (n = 352) } & & \multicolumn{3}{c}{ Girls (n = 368) } \\
\cline { 2 - 3 } & Class 1 & Class 2 & Class 3 & & Class 1 & Class 2 & Class 3 \\
\hline Latent class prevalence, $\%$ & 42.1 & 24.9 & 33.0 & & 18.7 & 47.6 & 33.7 \\
MVPA-weekdays, $\geq 30$ min/day & 0.7593 & 0.4360 & 0.0987 & & 0.7428 & 0.2034 & 0.2051 \\
MVPA-weekend days, $\geq 30$ min/day & 0.6217 & 0.1675 & 0.0317 & & 0.6831 & 0.0467 & 0.0000 \\
Traditional sports, $\geq 1$ sessions/3 days & 0.5915 & 0.3790 & 0.4659 & & 0.5561 & 0.2953 & 0.3551 \\
Fitness activities, $\geq 1$ sessions/3 days & 0.4380 & 0.3385 & 0.3996 & & 0.5368 & 0.2969 & 0.4682 \\
Other sports/playing, $\geq 1$ sessions/3 days & 0.4505 & 0.5339 & 0.2705 & & 0.4191 & 0.3725 & 0.4508 \\
Chores/work, $\geq 1$ sessions/3 days & 0.3920 & 0.4282 & 0.4079 & & 0.444 & 0.4618 & 0.5448 \\
Watching TV, $\geq 2$ hrs/day & 0.2545 & 0.6959 & 0.2606 & & 0.2356 & 0.4611 & 0.0644 \\
Watching DVDs or videos, $\geq 1$ hrs/day & 0.1809 & 0.6358 & 0.2552 & & 0.375 & 0.5374 & 0.1294 \\
Video/computer games, $\geq 1$ hrs/day & 0.3821 & 0.8599 & 0.2645 & & 0.0756 & 0.2312 & 0.0291 \\
Internet/computers, $\geq 1$ hrs/day & 0.3485 & 0.7175 & 0.5120 & & 0.422 & 0.8251 & 0.3193 \\
Talking/texting on phone, $\geq 1$ hrs/day & 0.1943 & 0.3371 & 0.3501 & & 0.2569 & 0.6537 & 0.2966 \\
Reading/homework, $\geq 2$ hrs/day & 0.2893 & 0.5467 & 0.4214 & & 0.5829 & 0.6014 & 0.4398 \\
\hline
\end{tabular}

Abbreviations: MVPA, moderate-to-vigorous physical activity; TV, television; DVD, digital video disc. 

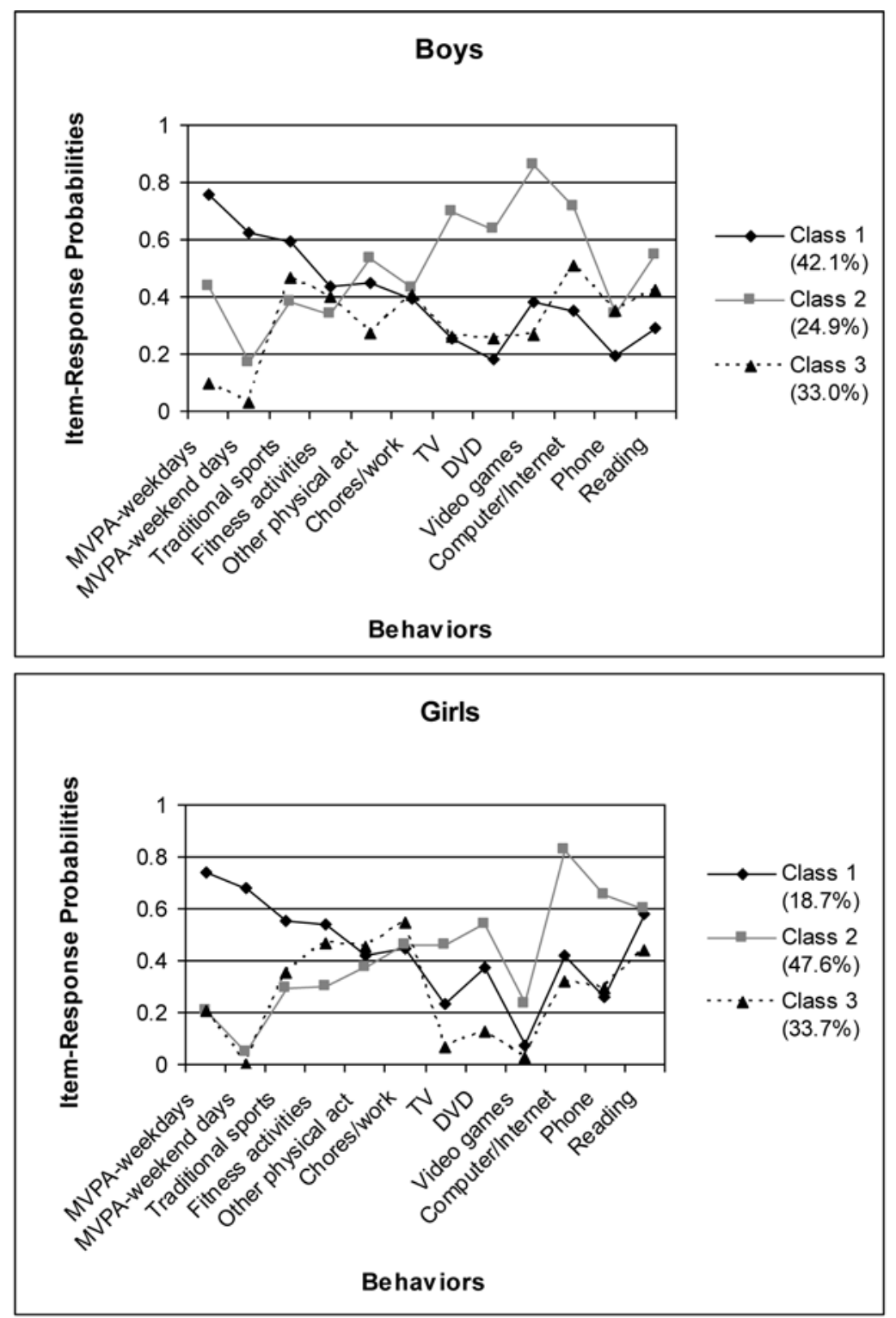

Figure 1 - Graphical displays of item-response probabilities across each of the 3 classes. Abbreviations: MVPA, moderate-tovigorous physical activity; TV, television; DVD, digital video disc.

Class 2 accounted for the largest segment of girls with an estimated prevalence of $47.6 \%$. Similar to boys in class 2, girls in this class had the highest probability of screen media use including using the Internet or computer (0.83) and watching DVDs/movies (0.54) for an hour or more per day, and watching TV for 2 or more hours per day (0.46). In addition, girls in class 2 also had the highest likelihood of texting or talking on the phone for an hour or more (0.65) and reading or doing homework for 2 or more hours (0.60). Girls in this class had low tendencies to participate in 30 minutes or more of MVPA on both weekdays (0.20) and weekends (0.05). Therefore, class 2 of girls was labeled as the "Sedentary" class.
Class 3, which comprised another $33.7 \%$ of the sample of girls, was similar to class 3 of boys in that they had relatively low to moderate probabilities for most of the behaviors compared with girls categorized in the other 2 classes. Girls in class 3 had the lowest probability for participating in MVPA for 30 minutes or more on weekend days $(0)$ and for all screen media activities (ie, TV, DVDs, computers, and video games). However, among the 3 girls' classes, girls in this class had the highest likelihood of participating in chores/work (0.54) and for other types of physical activities (0.45), possibly representing a "Low Media/Functional Activity" class of girls. Perhaps not surprising, the likelihood of 
playing video or computer games for an hour or more per day was relatively low for girls as compared with boys within each of the 3 classes.

\section{Class Demographics}

All youth were assigned to the class in which they had the highest posterior probability of membership. For boys, the average probability of correctly classifying each participant into each latent class was 0.82 for class 1 (Active), 0.74 for class 2 (Sedentary), and 0.78 for class 3 (Low Media/Moderate Activity). For girls, the average latent class probabilities for most likely latent class membership were $0.86,0.82$, and 0.77 for latent classes 1 (Active), 2 (Sedentary), and 3 (Low Media/Functional Activity), respectively, indicating good prediction of class membership.

To learn more about the 3 LCA-derived classes of boys and girls, chi-square procedures and latent multinomial logistic regression were completed to estimate associations with demographic characteristics. The results are presented in Table 6 in the form of column percentages with superscript letters indicating significant odds ratios comparing each class to one another. Among the classes of boys, those in the Active class had a significantly higher proportion $(P<.001)$ of 6 th to 8 th graders than 9th to 11th graders compared with the Sedentary and Low Media/Moderate Activity classes. Boys in the Sedentary class were significantly more likely to be overweight than boys in the Active class $(P<.05)$; however there were no differences in weight status between the Low Media/Moderate Activity class and either of the other 2 boys classes. There were no differences between the classes of boys in terms of race, parental education, family living arrangements, or percent receiving free or reduced-price lunch.

For girls, there were no differences in grade level, parent education, or receiving free or reduced-price lunch across the 3 classes. Members of the Sedentary class were significantly less likely to be white compared with girls in the Low Media/Functional Activity class $(P<.05)$. There were significant differences in the proportion of girls living with both parents; girls in the Sedentary class were significantly less likely to live with both parents together than girls in both the Active class $(P<.001)$ and the Low Media/Functional Activity $(P<.0001)$. Finally, higher proportions of girls in the Sedentary class were classified as overweight compared with girls in the Active $(P<.05)$ and Low Media/Functional Activity $(P<.05)$ classes.

\section{Discussion}

The primary aim of this study was to identify unique classes of children and adolescents based on their participation in a variety of physical activities and sedentary behaviors and then to explore the differences in demographics between the emergent classes. Using LCA, a 3 -class solution emerged as the best fitting model for both boys and girls. Indices of model fit were found to be acceptable and the latent classes represented meaningful classes that provide more detail than previous investigations that rely on unidimensional measures alone, such as whether children meet recommendations for particular activities.

In this sample, participation in MVPA was low with only $38 \%$ and $23 \%$ of youth participating in an average of 30 minutes or more per day on weekdays and weekend days, respectively. The Active class of boys was the largest of the 3 classes whereas the analogous class of girls was the smallest, which confirms the disparity previously shown between boys' and girls' in PA levels. ${ }^{33,34}$ Among boys, members in this class were more likely to be in middle school (6th-8th grade), confirming findings of other studies that show that younger children are typically more active than older youth. ${ }^{21,35,39}$ Girls in the Active class also had relatively high probabilities of read-

Table 6 Demographic Differences Among Emergent Latent Classes Based on Multinomial Logistic Regression

\begin{tabular}{|c|c|c|c|c|c|c|}
\hline \multirow[b]{3}{*}{ Variable } & \multicolumn{3}{|c|}{ Boys } & \multicolumn{3}{|c|}{ Girls } \\
\hline & $\begin{array}{l}\text { Class } 1 \\
\text { "Active" }\end{array}$ & $\begin{array}{c}\text { Class } 2 \\
\text { "Sedentary" }\end{array}$ & $\begin{array}{c}\text { Class } 3 \\
\text { "Low Media/ } \\
\text { Moderate Activity" }\end{array}$ & $\begin{array}{l}\text { Class } 1 \\
\text { "Active" }\end{array}$ & $\begin{array}{c}\text { Class } 2 \\
\text { "Sedentary" }\end{array}$ & $\begin{array}{c}\text { Class } 3 \\
\text { "Low Media/ } \\
\text { Functional Activity" }\end{array}$ \\
\hline & $\%$ & $\%$ & $\%$ & $\%$ & $\%$ & $\%$ \\
\hline 6th-8th grade & $65.3^{\mathrm{a}}$ & $40.5^{b}$ & $34.5^{\mathrm{b}}$ & 50.9 & 40.2 & 46.4 \\
\hline White race & 86.0 & 82.0 & 88.5 & $86.4^{\mathrm{ab}}$ & $79.4^{\mathrm{b}}$ & $88.8^{\mathrm{a}}$ \\
\hline $\begin{array}{l}\text { Parent education, } \\
\geq \text { college degree }\end{array}$ & 66.4 & 67.1 & 69.7 & 67.2 & 60.4 & 59.7 \\
\hline Live with 2 parents/guardians & 74.0 & 77.5 & 81.4 & $86.4^{\mathrm{a}}$ & $61.4^{\mathrm{b}}$ & $85.6^{\mathrm{a}}$ \\
\hline Free or reduced-price lunch & 11.3 & 14.6 & 8.0 & 11.9 & 14.7 & 10.4 \\
\hline Overweight & $22.7^{b}$ & $36.0^{\mathrm{a}}$ & $26.6^{\mathrm{ab}}$ & $15.3^{\mathrm{b}}$ & $29.9^{\mathrm{a}}$ & $20.0^{\mathrm{b}}$ \\
\hline
\end{tabular}

a,b Classes with different letters are significantly different at $P<.05$ based on multinomial logistic regression. Classes that share a letter are not significantly different. 
ing or doing homework, perhaps reflecting "productive sedentary behavior" as has been described elsewhere. ${ }^{40}$

These results may also have important implications for targeting obesity prevention efforts. Boys and girls in the class characterized by high screen media use and sedentary activities were significantly more likely to be classified as overweight or obese than youth in the other classes. This finding is congruent with other studies that demonstrate a relationship between the time children spend with media and childhood obesity. ${ }^{41-44}$ However, as others have pointed out ${ }^{40}$ it is important to continue exploring the relative contribution of each individual sedentary activity or screen behavior when trying to understand the etiology of obesity and related behaviors. While a sedentary class was identified for both boys and girls, the activities that dominated these classes differed. For boys, playing video games, using the computer, and watching TV were key while for girls, using the computer, the phone, and reading/homework stood out as main contributors.

The third class for both boys and girls highlights another large segment of youth (approximately a third of boys and girls) that are minimally or moderately engaged in most of the activities relative to the other segments. These classes may underscore the multifaceted nature of children and adolescents' lifestyles. For this group, it seems that there is no one activity that dominates their daily activities. Girls within this class appear to have their time occupied by chores and outside work in addition to time spent doing other sports and activities. While they show some level of interest in PA, for this group it may be the irregularity with which they participate in PA that separates them from the more active segment of youth.

Because this study is the first of its kind to develop and assess PA and sedentary behaviors using LCA, it is difficult to directly compare the results to other studies. However, a few studies were identified that used cluster analysis to classify and describe groups of children and adolescents based on their activity patterns. ${ }^{45-48}$ Marshall et $\mathrm{al}^{48}$ described patterns of sedentary and PA behavior in a sample of US and UK children aged 11 to 15 years old through gender-specific cluster analysis. Three similar clusters were found for both boys and girls: one cluster reported high levels of PA, playing video games, watching television, and for girls, talking on the telephone ("techno-active" for boys and "sociable actives" for girls), the second cluster reported high PA and fewer social sedentary behaviors such as talking on the telephone ("non-socializing actives"), and the third cluster was characterized as inactive, with members reporting lower levels of both physical and sedentary activities compared with the other groups ("uninvolved inactives"). ${ }^{48}$

The current study has a number of limitations that should be noted. First, the study sample was limited to families within 1 metropolitan area within the Midwest, was predominantly white, and was of higher socioeconomic background. Baseline data collection for the IDEA and ECHO studies took place between the months of September and May, months which experience average daily temperatures between approximately 13 and 58 degrees Fahrenheit and an average range of snowfall between 0.5 to 10 inches. ${ }^{49}$ Therefore, results of this study regarding PA behaviors may not be generablizable to all youth of this age or to youth from other geographical regions.

In addition, a different method of categorizing PA and sedentary behaviors could have resulted in a somewhat different latent class structure. For example, applying a higher cut point (such as 60 minutes per day) when dichotomizing MVPA may have resulted in alternative distinctions between classes. However, because youth in this sample were only participating in an average of 29 minutes and 21 minutes of MVPA on weekdays and weekend days, respectively, splitting these variables at 30 minutes was more appropriate. While dichotomizing variables is an approach that is commonly applied in LCA methods and may help in the communication and application of findings, there may be some loss of sensitivity that results from categorizing the data this way. Furthermore, this analysis did not distinguish voluntary (ie, discretionary) activities versus nonvoluntary (ie, school-based) activities. For example, the measure of reading included any reading that was done during youth's leisure-time as well as any reading that was associated with homework or that took place during the school day. Lastly, because the probability of membership in a particular class did not equal 1 for each individual, there is some uncertainty associated with assigning individuals to their respective latent class. Because this uncertainty was not modeled in the multinomial logistic regression, it is important that the results be interpreted as such. ${ }^{28}$

Nonetheless, these analyses have shown the merits of LCA for the purpose of identifying and describing groups of children and adolescents based on their distinct PA and sedentary behaviors, and have provided potential contextual explanations for the patterns observed. Strengths include the relatively large size of the sample, which includes an even distribution of boys and girls that span the middle school and high school age ranges. A variety of PA and sedentary behaviors were measured using a variety of data collection methods, including measurement of PA via accelerometers. In addition, while cross-sectional analyses are typically viewed as a limitation in observational research, in LCA, the latent variable is assumed to be static or unchanging making the use of cross-sectional data appropriate.

The categorization and characterization of segments of youth in this study provides important information for the identification, framing, and tailoring of specific communication messages and intervention strategies. For example, during intervention planning stages the latent classes identified in this study could be used to stratify youth into appropriate groups for formative research such as focus groups. Discussions to identify salient messages and appropriate activities could be conducted to try to maximize reach and relevancy among the target audience. These profiles can be used more broadly to guide programs targeted toward these types of youth, and more specifically to match youth to tailored interventions. 
Given the significant concern regarding the high prevalence of overweight and obesity among youth in this country, these findings may be very useful as part of the empirical basis in the guidance and planning of tailored and targeted interventions based on patterns of behaviors.

\section{Acknowledgments}

The IDEA study was supported by the National Cancer Institute's Transdisciplinary Research in Energetics and Cancer (TREC) Initiative (1 U54 CA116849-01, Examining the Obesity Epidemic Through Youth, Family \& Young Adults, PI: Robert Jeffery, $\mathrm{PhD}$ ). The ECHO study was supported by the National Heart, Lung, and Blood Institute (R01HL085978). The content of this manuscript is solely the responsibility of the authors and does not necessarily represent the official views of the National Institutes of Health.

\section{References}

1. US Department of Health and Human Services. Physical activity and health: a report of the Surgeon General. Atlanta, GA: Department of Health and Human Services, Centers for Disease Control and Prevention, National Center for Chronic Disease Prevention and Health Promotion; 1996.

2. Strong WB, Malina RM, Blimkie CJ, et al. Evidence based physical activity for school-age youth. J Pediatr. 2005;146:732-737.

3. US Department of Health and Human Services. 2008 Physical Activity Guidelines for Americans; 2008.

4. Weinsier RL, Hunter GR, Heini AF, Goran MI, Sell SM. The etiology of obesity: relative contribution of metabolic factors, diet, and physical activity. Am J Med. 1998;105:145-150.

5. Raudsepp L, Viira R. Changes in physical activity in adolescent girls: a latent growth modeling approach. Acta Paediatr. 2008;97:647-652.

6. Andreasen AR. Marketing social change: changing behavior to promote health, social development, and the environment. San Francisco: Jossey-Bass; 1995.

7. Maibach EW, Parrott RL, eds. Designing health messages: approaches from communication theory and public health practice. Thousand Oaks, CA: Sage; 1995.

8. Slater MD. Theory and method in health audience segmentation. J Health Commun. 1996;1:267-283.

9. Dierker LC, Vesel F, Sledjeski EM, Costello D, Perrine N. Testing the dual pathway hypothesis to substance use in adolescence and young adulthood. Drug Alcohol Depend. 2007;87:83-93.

10. Agrawal A, Lynskey MT, Madden PA, Bucholz KK, Heath AC. A latent class analysis of illicit drug abuse/ dependence: results from the National Epidemiological Survey on Alcohol and Related Conditions. Addiction. 2007;102:94-104.

11. Reboussin BA, Song EY, Shrestha A, Lohman KK, Wolfson M. A latent class analysis of underage problem drinking: evidence from a community sample of 16-20 year olds. Drug Alcohol Depend. 2006;83:199-209.
12. Rose JS, Chassin L, Presson C, Sherman SJ, Stein MD, $\mathrm{Col} \mathrm{N}$. A latent class typology of young women smokers. Addiction. 2007;102:1310-1319.

13. Padmadas SS, Dias JG, Willekens FJ. Disentangling women's responses on complex dietary intake patterns from an Indian cross-sectional survey: a latent class analysis. Public Health Nutr. 2006;9:204-211.

14. Patterson BH, Dayton CM, Graubard BI. Latent class analysis of complex survey data: application to dietary data. JASA. 2002;97:721-729.

15. Duncan AE, Bucholz KK, Neuman RJ, Agrawal A, Madden PA, Heath AC. Clustering of eating disorder symptoms in a general population female twin sample: a latent class analysis. Psychol Med. 2007;37:1097-1107.

16. Metzger JS, Catellier DJ, Evenson KR, Treuth MS, Rosamond WD, Siega-Riz AM. Patterns of objectively measured physical activity in the United States. Med Sci Sports Exerc. 2008;40:630-638.

17. Lytle L. Examining the etiology of childhood obesity: the IDEA study. Am J Community Psychol. 2009;44:338-349.

18. Widome R, Forster JL, Hannan PJ, Perry CL. Longitudinal patterns of youth access to cigarettes and smoking progression: Minnesota Adolescent Community Cohort (MACC) study (2000-2003). Prev Med. 2007;45:442-446.

19. Trost SG, Ward DS, Moorehead SM, Watson PD, Riner W, Burke JR. Validity of the computer science and applications (CSA) activity monitor in children. Med Sci Sports Exerc. 1998;30:629-633.

20. Freedson P, Pober D, Janz KF. Calibration of accelerometer output for children. Med Sci Sports Exerc. 2005;37:S523S530.

21. Troiano RP, Berrigan D, Dodd KW, Masse LC, Tilert T, McDowell M. Physical activity in the United States measured by accelerometer. Med Sci Sports Exerc. 2008;40:181-188.

22. Kuo J, Schmitz KH, Evenson KR, et al. Physical and social contexts of physical activities among adolescent girls. $J$ Phys Act Health. 2009;6:144-152.

23. Kohl HW, Fulton JE, Caspersen CJ. Assessment of physical activity among children and adolescents: a review and synthesis. Prev Med. 2001;31:S54-S76.

24. Sallis JF, Buono MJ, Roby JJ, Micale FG, Nelson JA. Seven-day recall and other physical activity self-reports in children and adolescents. Med Sci Sports Exerc. 1993;25:99-108.

25. Gortmaker SL, Peterson K, Wiecha J, et al. Reducing obesity via a school-based interdisciplinary intervention among youth: Planet Health. Arch Pediatr Adolesc Med. 1999;153:409-418.

26. Utter J, Neumark-Sztainer D, Jeffery R, Story M. Couch potatoes or French fries: are sedentary behaviors associated with body mass index, physical activity, and dietary behaviors among adolescents? J Am Diet Assoc. 2003;103:1298-1305.

27. American Academy of Pediatrics, Committee on Public Education. American Academy of Pediatrics: children, adolescents, and television. Pediatrics. 2001;107:423-426.

28. Lanza ST, Collins JL, Lemmon D, Schafer JL. PROC LCA: a SAS procedure for latent class analysis. Struct Equ Modeling. 2007;14:671-694.

29. Hagenaars JA, McCutcheon A. Applied latent class analysis. Cambridge: Cambridge University Press; 2002. 
30. Lanza ST, Flaherty B, Collins LM. Latent class and latent transition analysis. In: Schinka J, Velicer W, eds. Research methods in psychology. Hoboken, NJ: John Wiley \& Sons, Inc.; 2003:663-685.

31. Akaike H. Factor analysis and the AIC. Psychometrika. 1987;52:317-332.

32. Raftery AE. Bayesian model selection in social research. Sociol Methodol. 1995;25:111-163.

33. Sallis JF, Alcaraz JE, McKenzie TL, Hovell MF. Predictors of change in children's physical activity over 20 months. Variations by gender and level of adiposity. Am J Prev Med. 1999;16:222-229.

34. Duncan SC, Duncan TE, Strycker LA, Chaumeton NR. A cohort-sequential latent growth model of physical activity from ages 12 to 17 years. Ann Behav Med. 2007;33:80-89.

35. Kahn JA, Huang B, Gillman MW, et al. Patterns and determinants of physical activity in U.S. adolescents. $J$ Adolesc Health. 2008;42:369-377.

36. van Mechelen W, Twisk JW, Post GB, Snel J, Kemper HC. Physical activity of young people: the Amsterdam Longitudinal Growth and Health Study. Med Sci Sports Exerc. 2000;32:1610-1616.

37. Kuczmarski RJ, Odgen CL, Grummer-Strawn LM, et al. CDC growth charts: United States. Advance data from vital and health statistics. Hyattsville, Maryland: National Center for Health Statistics; 2000.

38. Barlow SE, Expert C. Expert committee recommendations regarding the prevention, assessment, and treatment of child and adolescent overweight and obesity: summary report. Pediatrics. 2007;120(Suppl 4):S164-S192.

39. Nader PR, Bradley RH, Houts RM, McRitchie SL, O'Brien M. Moderate-to-vigorous physical activity from ages 9 to 15 years. JAMA. 2008;300:295-305.

40. Feldman DE, Barnett T, Shrier I, Rossignol M, Abenhaim L. Is physical activity differentially associated with different types of sedentary pursuits? Arch Pediatr Adolesc Med. 2003;157:797-802.
41. Andersen RE, Crespo CJ, Bartlett SJ, Cheskin LJ, Pratt M. Relationship of physical activity and television watching with body weight and level of fatness among children: results from the Third National Health and Nutrition Examination Survey. JAMA. 1998;279:938-942.

42. Dietz WH, Gortmaker SL. TV or not TV: fat is the question. Pediatrics. 1993;91:499-501.

43. Gortmaker SL, Must A, Sobol AM, Peterson K, Colditz GA, Dietz WH. Television viewing as a cause of increasing obesity among children in the United States, 1986-1990. Arch Pediatr Adolesc Med. 1996;150:356-362.

44. Marshall SJ, Biddle SJ, Gorely T, Cameron N, Murdey I. Relationships between media use, body fatness and physical activity in children and youth: a meta-analysis. Int J Obes. 2004;28:1238-1246.

45. Nelson MC, Gordon-Larsen P, Adair LS, Popkin BM. Adolescent physical activity and sedentary behavior: patterning and long-term maintenance. Am J Prev Med. 2005;28:259-266.

46. Gorely T, Marshall SJ, Biddle SJ, Cameron N. Patterns of sedentary behaviour and physical activity among adolescents in the United Kingdom: Project STIL. J Behav Med. 2007;30:521-531.

47. Zabinski MF, Norman GJ, Sallis JF, Calfas KJ, Patrick K. Patterns of sedentary behavior among adolescents. Health Psychol. 2007;26:113-120.

48. Marshall SJ, Biddle SJH, Sallis JF, McKenzie TL, Conway TL. Clustering of sedentary behaviors and physical activity among youth: a cross-national study. Pediatr Exer Sci 2002 14:401-417.

49. Minnesota Climatology Working Group, State Climatology Office. Minneapolis/St. Paul Monthly Average Temperature Time-Series (1891-2008). Available from: http://climate.umn.edu/doc/twin_cities/twin_cities.htm 